\title{
Opiate Exposure and Withdrawal Induces a Molecular Memory Switch in the Basolateral Amygdala between ERK1/2 and CaMKII $\alpha$-Dependent Signaling Substrates
}

\author{
Danika Lyons, ${ }^{1}$ Xavier de Jaeger, ${ }^{1}$ Laura G. Rosen, ${ }^{1}$ Tasha Ahmad, ${ }^{1}$ Nicole M. Lauzon, ${ }^{1}$ Jordan Zunder, ${ }^{1}$ \\ Lique M. Coolen, ${ }^{1}$ Walter Rushlow, ${ }^{1,2}$ and Steven R. Laviolette ${ }^{1,2,3}$ \\ ${ }^{1}$ Department of Anatomy \& Cell Biology, ${ }^{2}$ Department of Psychiatry, ${ }^{3}$ Department of Psychology, Schulich School of Medicine \& Dentistry, University of \\ Western Ontario, London, Ontario N6A 5C1, Canada
}

\begin{abstract}
Opiate reward memories are powerful triggers for compulsive opiate-seeking behaviors. The basolateral amygdala (BLA) is an important structure for the processing of opiate-related associative memories and is functionally linked to the mesolimbic dopamine (DA) pathway. Transmission through intra-BLA DA D1-like and D2-like receptors independently modulates the formation of opiate reward memories as a function of opiate-exposure state. Thus, in the opiate-naive state, intra-BLA D1 transmission is required for opiate-related memory formation. Once opiate dependence and withdrawal has developed, a functional switch to a DA D2-mediated memory mechanism takes place. However, the downstream molecular signaling events that control this functional switch between intra-BLA DA D1 versus D2 receptor transmission are not currently understood. Using an unbiased place conditioning procedure in rats combined with molecular analyses, we report that opiate reward memory acquisition requires intra-BLA ERK1/2 signaling only in the previously opiate-naive state. However, following chronic opiate exposure and withdrawal, intra-BLA reward memory processing switches to a CaMKII $\alpha$-dependent memory substrate. Furthermore, the ability of intra-BLA DA D1 or D2 receptor transmission to modulate the motivational salience of opiates similarly operates through a D1-mediated ERK-dependent mechanism in the opiate-naive state, but switches to a D2-mediated CaMKII $\alpha$-dependent mechanism in the dependent/withdrawn state. Protein analysis of BLA tissue revealed a downregulation of ERK1/2 phosphorylation and a dramatic reduction in both total and phosphorylated CaMKII $\alpha$ signaling, specifically in the opiate-dependent/ withdrawn state, demonstrating functional control of ERK1/2-dependent versus CaMKII $\alpha$-dependent memory mechanisms within the BLA, controlled by opiate-exposure state.
\end{abstract}

\section{Introduction}

The basolateral nucleus of the amygdala (BLA) is critical for the processing of reward-related associative learning, including opiate-related memory formation (Lintas et al., 2011; Frenois et al., 2005; Stuber et al., 2011; Sun and Laviolette, 2012). Anatomically, the BLA receives functional dopamine (DA) inputs from the ventral tegmental area (VTA) and provides outputs to neurons in the nucleus accumbens (NAc; Floresco et al., 1998, 2001; Bissière et al., 2003; Ford et al., 2006), two regions that are critical for opiate-related reward processing. Although the BLA is not involved in processing the primary reinforcing effects of opiates (Olmstead and Franklin, 1997), intra-BLA DAergic transmission modulates the acquisition of opiate-related associative memo-

Received March 21, 2013; revised July 22, 2013; accepted July 25, 2013.

Author contributions: D.L., W.R., and S.R.L. designed research; D.L., X.d.J., T.A., N.M.L., J.Z., L.M.C., W.R., S.R.L., and L.G.R. performed research; D.L., X.d.J., T.A., N.M.L., J.Z., L.M.C., W.R., S.R.L., and L.G.R. analyzed data; D.L. wrote the paper.

This work was supported by the Canadian Institutes of Health Research and an Natural Sciences and Engineering Research Council of Canada fellowship to N.M.L.

Correspondence should be addressed to Steven R. Laviolette, Department of Anatomy \& Cell Biology, Department of Psychiatry, University of Western Ontario, London, ON N6A 5C1, Canada. E-mail: steven.laviolette@schulich.uwo.ca.

DOI:10.1523/JNEUROSCI.1226-13.2013

Copyright $\odot 2013$ the authors $\quad 0270-6474 / 13 / 3314693-12 \$ 15.00 / 0$ ries. While D1 receptor (D1R) transmission is critical for acute opiate reward learning, following chronic opiate exposure and withdrawal, opiate-related memory acquisition processing switches to a D2 receptor (D2R)-dependent substrate (Lintas et al., 2011, 2012). However, the downstream molecular mechanisms controlling DAergic modulation of opiate reward memory within the BLA are not currently understood.

Two molecules linked to DAergic transmission and important for drug-related memory formation are the extracellular-signalrelated kinases 1 and $2(\mathrm{ERK} 1 / 2)$ and calcium/calmodulindependent protein kinase II- $\alpha$ (CaMKII $\alpha)$. Cues linked to drug reward in rodents, including cocaine, amphetamine, and opiates, modulate ERK expression within various reward-related neural regions (Mizoguchi et al., 2004; Lu et al., 2005; Miller and Marshall, 2005; Valjent et al., 2006; Girault et al., 2007; Li et al., 2010, 2011). Similarly, CaMKII $\alpha$ is linked to various forms of drugrelated memory formation. Reinstatement of morphine seeking is correlated with CaMKII $\alpha$ phosphorylation in the NAc while CaMKII inhibition prevents these behaviors (Liu et al., 2012a,b). Finally, long-term methadone exposure strongly downregulates CaMKII $\alpha$ in several neural regions in rat brain (Andersen et al., 2012), suggesting that opiate exposure may modulate CaMKII $\alpha$ levels in the mammalian brain. Both D1R and D2R activation 
is associated with downstream modulation of ERK1/2 and CaMKII $\alpha$ pathways. Nevertheless, D1 and D2 receptors show functional dissociations in terms of ERK versus CaMKII $\alpha$ functional linkages, with D1 receptor activation within the mesocorticolimbic system linked tightly to ERK phosphorylation (Kelly et al., 2003; Alvarez-Jaimes et al., 2005; Girault et al., 2007; Li et al., 2010; Fricks-Gleason and Marshall, 2011) versus D2 receptor activation, which has been functionally linked to downstream CaMKII modulatory effects (Liu et al., 2009; Fricks-Gleason and Marshall, 2011). Given previous evidence demonstrating a shift between D1R-dependent versus D2R-dependent memory substrates within the BLA following chronic opiate exposure and withdrawal (Lintas et al., 2011, 2012), we hypothesized that intraBLA opiate reward memory processing may switch from an ERK-sensitive, D1 receptor-dependent substrate to a CaMKII $\alpha$ sensitive, D2 receptor-dependent substrate as a function of opiate exposure. Using behavioral and molecular analyses, we compared the function and expression of ERK1/2 versus CaMKII $\alpha$ signaling during the formation of opiate-related reward memories across the opiate-naive versus dependent and withdrawn states. Our findings demonstrate a novel molecular switch between a D1-dependent, ERK1/2-sensitive memory substrate active during acute opiate memory formation to a D2-dependent, CaMKII $\alpha$-sensitive memory substrate activated during chronic opiate exposure and withdrawal.

\section{Materials and Methods}

Surgical procedures. Male Sprague Dawley rats $(350-400 \mathrm{~g}$ at the start of the experiments; Charles River) were anesthetized with a ketamine (80 $\mathrm{mg} / \mathrm{ml})$ xylazine $(6 \mathrm{mg} / \mathrm{ml})$ mixture and placed into a stereotaxic device. Stainless steel guide cannulae (22 gauge; Plastics One) were bilaterally implanted into our brain regions of interest using the following stereotaxic coordinates: for the VTA $\left(10^{\circ}\right.$ angle), from bregma, anteroposterior (AP) $-5.0 \mathrm{~mm}$, lateral (L) $\pm 2.6 \mathrm{~mm}$, from the dural surface, ventral (V) $-8.0 \mathrm{~mm}$; for the BLA ( $0^{\circ}$ angle), from bregma AP $-2.6 \mathrm{~mm}, \mathrm{~L} \pm 5.0$ $\mathrm{mm}$; from the dural surface, $\mathrm{V}-7.2 \mathrm{~mm}$. At the conclusion of the experiments, rats were deeply anesthetized and transcardially perfused with isotonic saline followed by $10 \%$ formalin. Brains were then removed, placed into a formalin-sucrose solution and stored in the refrigerator for a minimum $48 \mathrm{~h}$ before sectioning. All brains were sectioned in $40 \mu \mathrm{m}$ slices in a cryostat. Sections were stained with cresyl violet and VTA or BLA cannulae placements were verified using light microscopy according to the anatomical boundaries defined by Paxinos and Watson (2005). Rats found to have cannulae placements outside of the desired brain regions were excluded from analysis. All surgical procedures and protocols were approved by Canadian Federal and Institutional Animal Care Guidelines.

Drug treatments. The highly selective ERK1/2 inhibitor UO126 (Tocris Bioscience) was dissolved in a solution of $50 \%$ dimethyl sulfoxide and $50 \%$ physiological saline, $\mathrm{pH}$ adjusted to 7.4 . The CaMKII inhibitors KN-62 and autocamtide-2-related inhibitory peptide (AIP; Tocris Bioscience), selective DA D1R-like agonist SKF-81297 (Tocris Bioscience), the selective DA D2R-like agonist quinpirole (Sigma-Aldrich), morphine (morphine hydrochloride, MacFarlane Smith), and heroin (diacetylmorphine, MacFarlane Smith) were dissolved in physiological saline, $\mathrm{pH}$ adjusted to 7.4. Bilateral BLA or VTA microinjections $(0.5 \mu \mathrm{l}$ of volume per infusion) were performed over $1 \mathrm{~min}$ via plastic tubing connected to a $1 \mu \mathrm{l}$ Hamilton microsyringe. Injectors were left in place an additional 1 min to ensure adequate diffusion from the injector tip. Intra-BLA microinfusions of ERK or CaMKII inhibitors were performed immediately before systemic injections of morphine or saline vehicle, and rats were then placed into the assigned conditioning environments immediately following injections of morphine or saline. For intra-VTA morphine trials, BLA microinfusions of ERK or CaMKII inhibitors were performed immediately before intra-VTA microinfusions of morphine or saline. For intra-BLA DA receptor activation coupled with ERK or CaMKII inhibitors, the D1R agonist SKF 81297 and ERK inhibitor U0126 or the D2R agonist quinpirole and CaMKII inhibitor KN-62 were coadministered before systemic injections of morphine or saline. For morphine conditioned place preference (CPP) experiments, either suprareward threshold ( $5 \mathrm{mg} / \mathrm{kg}$, i.p.) or subreward threshold ( $0.05 \mathrm{mg} / \mathrm{kg}$, i.p.) conditioning doses of morphine were used, corresponding to effective versus ineffective morphine doses for producing behavioral CPP (Bishop et al., 2011; Lintas et al., 2012).

Place conditioning procedure. An unbiased, fully counterbalanced CPP procedure was used, as described previously (Bishop et al., 2011; Lintas et al., 2011). Briefly, saline or morphine (systemic or intra-VTA) was paired with one of two environments, which differed in terms of color, texture, and smell. Following recovery from surgery, rats were randomly assigned to an experimental group. All rats were exposed to a preconditioning phase where they were placed into a motivationally neutral gray box for $20 \mathrm{~min}$. The following day, the $8 \mathrm{~d}$ conditioning phase commenced. One conditioning environment was white with a wire-mesh floor covered in woodchips. The alternate environment was black with a smooth Plexiglas floor wiped down with $2 \%$ acetic acid immediately before the animal was placed into it. Experimental treatments were fully counterbalanced within groups. As has been reported previously, rats display no baseline preference for either of these environments (Laviolette and van der Kooy, 2003). During conditioning, rats receive an equal number of morphineenvironment versus saline-environment pairings. Therefore, over the $8 \mathrm{~d}$ procedure, rats receive four $30 \mathrm{~min}$ morphine-environment pairings and four 30 min saline-environment pairings. During testing, rats are placed on a narrow gray zone separating the two test environments and time spent in each environment is digitally recorded and scored separately for each animal over a 10 min test session. All rats are tested in a drug-free state.

Induction of opiate dependence and withdrawal. For experimental groups conditioned in the opiate-dependent/withdrawn state, opiate dependence and withdrawal was induced as described previously (Lintas et al., 2011; De Jaeger et al., 2012). This involves a $7 \mathrm{~d}$ exposure phase of daily $0.5 \mathrm{mg} / \mathrm{kg}$ subcutaneous injections of heroin before the beginning of behavioral conditioning (yoked control groups receive saline vehicle). Following this exposure phase, rats are conditioned $21 \mathrm{~h}$ after their last heroin injection. During the conditioning phase, heroin injections are administered as a maintenance dose $2.5 \mathrm{~h}$ after the termination of each conditioning session. Thus, rats receive a total of 15 heroin $(0.5 \mathrm{mg} / \mathrm{kg}$, s.c.) injections over the course of an experiment. The aversive effects of withdrawal induced by this regimen are qualitatively similar to those observed after a 3 week regimen of morphine administration, which produces aversive motivational effects (conditioned place aversions) as well as somatic withdrawal signs (Laviolette and van der Kooy, 2004), demonstrating strong opiate dependence following this exposure regimen.

Western blot procedure. Two groups of eight rats received either daily heroin $(0.5 \mathrm{mg} / \mathrm{kg}$, s.c.) or saline injections, analogous to the opiatedependence/withdrawal protocol used in behavioral conditioning experiments. Twenty-one hours following their last injection, rats were killed and the brains rapidly removed, and a micropunch of the amygdala obtained. Amygdalar tissue samples were then homogenized using a Dounce homogenizer and protein isolated using a Noindent P40/SDS lysis buffer (137 mm NaCl, 20 mm Tris, pH 8.0, 1\% NP-40, 10\% glycerol, and $0.1 \%$ SDS) containing a protease inhibitor tablet (Mini cOmplete tablets, Roche) and phosphatase inhibitors (Calbiochem phosphatase inhibitor mixture set 4; Sigma-Aldrich phosphatase inhibitor mixture 2). Following homogenization and centrifugation at $4^{\circ} \mathrm{C}$ to remove debris, the samples were mixed with an equal volume of $2 \times$ Laemmli loading buffer and heated to $95^{\circ} \mathrm{C}$ for $5 \mathrm{~min}$ before storage in an $-80^{\circ} \mathrm{C}$ freezer until needed. Twenty-five micrograms of protein from control (opiate-naive) or treatment (heroin-dependent/withdrawn) samples were loaded onto $12 \%$ denaturing SDS-PAGE gels. Samples were then subjected to electrophoresis in a Bio-Rad Mini Protein 3 Western blotting apparatus with Tris/glycine/SDS buffer (Bio-Rad Cube Solutions) at $125 \mathrm{~V}$ for $1.5 \mathrm{~h}$. Bio-Rad Kaleidoscope molecular weight standards were included on the gels to confirm the molecular weight of the proteins of interest. Following electrophoresis, protein was transferred from the gels 

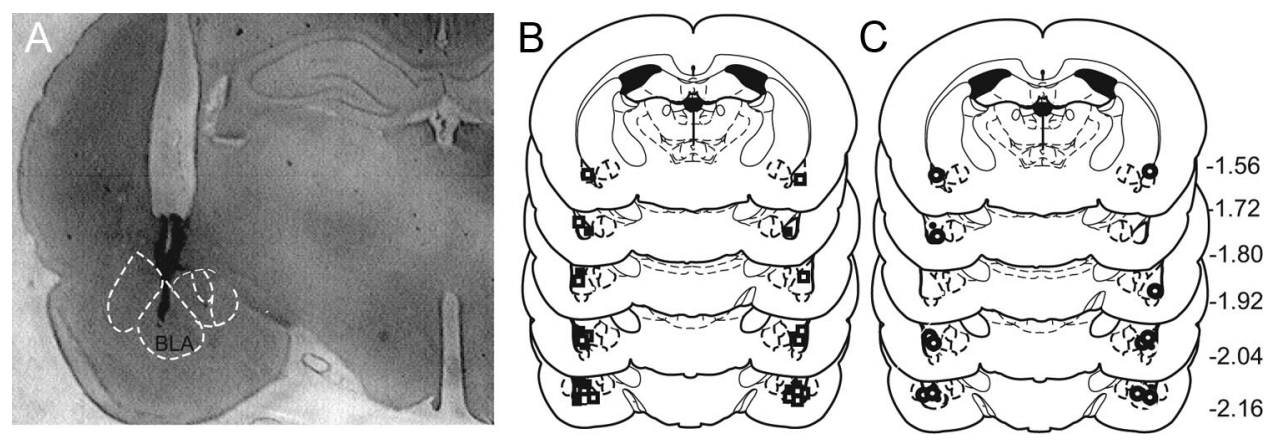

Figure 1. Histological analyses. $\boldsymbol{A}$, Microphotograph of a representative bilateral intra-BLA guide cannulae and injector tip placement. $\boldsymbol{B}$, Schematic representation of bilateral intra-BLA injector tip placements. $\square$, Previously opiate-naive rats receiving intra-BLA U0-126 (1.0 $\mu \mathrm{g} / 0.5 \mu \mathrm{l}) ; \square$, previously opiate-naive rats receiving intra-BLA KN-62 (1.0 $\mu \mathrm{g} / 0.5$ $\mu \mathrm{l})$. C, Schematic representation of bilateral intra-BLA injector tip placements. O, 0piate-dependent/withdrawn rats receiving intra-BLA KN- $62(1.0 \mu \mathrm{g} / 0.5 \mu \mathrm{l}) ; \bigcirc, 0$ piate-dependent/ withdrawn rats receiving intra-BLA U0126 (1.0 $\mu \mathrm{g} / 0.5 \mu \mathrm{l})$.

onto a nitrocellulose membrane (Bio-Rad) using a Mini Trans-Blot apparatus (Bio-Rad) with a Tris/glycine/methanol solution (Bio-Rad Cube Solutions) at $75 \mathrm{~V}$ for $1 \mathrm{~h}$. To ensure that protein samples were relatively equally loaded and proper protein separation and transfer was achieved, the membranes were stained using Ponceau S. To identify changes in the level of phosphorylated total proteins, the blots were blocked with $5 \%$ nonfat dry milk (NFDM) in TBS-T for $1 \mathrm{~h}$ at room temperature with rocking. Following blocking, the membranes were incubated in a solution containing 5\% NFDM in TBS-T along with an antibody directed against either phosphorylated ERK1/2 (Thr202/Tyr204), CaMKII Thr286, or goat anti-CaMKII $\beta$ overnight at $4^{\circ} \mathrm{C}$ with rocking. Following incubation in the primary antibody solution, blots were washed in TBS-T three times for $15 \mathrm{~min}$. Last, a solution containing 5\% dried nonfat milk (Carnation) in TBS-T and a secondary antibody (HRP-conjugated goatanti-rabbit antibody) was applied to the blots and left to incubate for $1 \mathrm{~h}$ at room temperature. Following three washes in TBS-T, the protein of interest was detected using chemiluminescence (Super-Signal, Thermo Scientific) and Kodak X-OMAT LS film. The blots were then stripped (Restore Western Blot Stripping Buffer, Thermo Scientific) and reprobed for total ERK1/2, CaMKII $\alpha$, or CaMKII $\beta$ and detected using chemiluminescence and film. Finally, the blots were restripped and probed one final time for $\alpha$-tubulin (loading control). Densitometry measurements were obtained using Kodak digital analysis software and the data analyzed using Microsoft Excel. Antibody dilutions were as follows: $\alpha$-tubulin (rabbit, 1:50,000; Sigma-Aldrich), ERK1/2 (rabbit, 1:10,000; Cell Signaling Technology), pERK1/2 (rabbit: 1:2000; Cell Signaling Technology), CaMKII $\alpha$ (rabbit, 1:2000; Cell Signaling Technology), phosphorylated CaMKII (rabbit, 1:5000; Cell Signaling Technology), and CaMKII $\beta$ (goat, 1:200; Santa Cruz Biotechnology).

\section{Results}

Intra-BLA inhibition of ERK but not CaMKII signaling blocks morphine reward memory acquisition in the opiate-naive state Analysis of intra-BLA microinjector placements revealed cannulae tip locations within the anatomical boundaries of the BLA as defined by Paxinos and Watson (2005). In Figure 1A, we present a representative microphotograph showing a typical intra-BLA microinjector placement. In Figure $1 B, C$, we present a schematic depiction of representative experimental groups. Analysis of CPP behavioral scores revealed that bilateral intra-BLA microinfusions of the highly selective ERK1/2 inhibitor U0126 (0.1-1.0 $\mu \mathrm{g} / 0.5 \mu \mathrm{l})$ dose-dependently blocked the acquisition of morphine reward memory, as measured in the CPP paradigm, in rats conditioned in a previously opiate-naive state, but not in rats conditioned while in a state of opiate dependence and withdrawal (Fig. 2). Two-way repeated-measures ANOVA revealed a significant group by treatment interaction on time spent in salinepaired versus morphine-paired environments $\left(F_{(2,45)}=29.8, p<\right.$ $0.0001)$. Post hoc analyses revealed that, whereas rats treated with
intra-BLA UO126 at a higher concentration $(1.0 \mu \mathrm{g} / 0.5 \mu \mathrm{l})$ displayed no significant preference for morphine-paired environments $(n=8 ; p>0.05)$, intra-BLA UO126 at the lower concentration $(n=8 ; 0.1 \mu \mathrm{g} / 0.5 \mu \mathrm{l})$ or vehicle control rats $(n=$ 7) demonstrated significant CPP for morphine-paired environments (all $p<0.01$; Fig. $2 A$ ). Furthermore, comparing only time spent in the morphine-paired environments, a significant difference between groups on the time spent in the morphine-paired side was revealed with intra-BLA vehicle or low-dose UO126 groups spending significantly more time in the morphine-paired side than those in the high-dose UO126 group (all $p<0.01$ ).

To examine the effect of CaMKII inhibition on opiate reward memory acquisition, bilateral intra-BLA microinfusions of KN-62 $(0.05-1.0 \mu \mathrm{g} / 0.5 \mu \mathrm{l})$ were administered to rats in the previously opiate-naive state $(n=7,7,8$, respectively; vehicle controls $n=7)$. At all doses tested $(0.05-1.0 \mu \mathrm{g} / 0.5 \mu \mathrm{l})$ intra-BLA injections of the CaMKII inhibitor KN-62 failed to block the acquisition of morphine CPP in previously opiate-naive rats, with all groups demonstrating robust morphine-environment $\mathrm{CPP}$, relative to vehicle controls (Fig. $2 B$ ). Two-way repeatedmeasures ANOVA revealed a significant group by treatment interaction on time spent in the morphine-paired versus saline-paired environments $\left(F_{(2,43)}=6.0, p<0.01\right)$ in rats receiving intra-BLA $\mathrm{KN}-62$. Post hoc analyses revealed that, relative to vehicle controls, rats treated with intra-BLA KN-62 spent significantly more time in the morphine-paired than saline-paired environment at all doses of KN-62 [0.05-1.0 $\mu \mathrm{g} / 0.5 \mu \mathrm{l}$; all $p<0.01$; Fig. $2 B$; for ease of comparison, intra-BLA vehicle control group data $(n=7)$ is shown in both $A$ and $B$ ]. These experiments indicate that pharmacological inhibition of MEK phosphorylation, but not CaMKII phosphorylation, within the BLA dose-dependently blocks the acquisition of associative opiate reward memory in rats conditioned in the previously opiate-naive state.

\section{Intra-BLA inhibition of CaMKII signaling or CaMKII autophosphorylation blocks morphine reward memory acquisition only in the opiate-dependent/withdrawn state}

We next compared the effects of intra-BLA CaMKII inhibition versus ERK1/2 inhibition on morphine reward memory acquisition in rats trained in an opiate-dependent/withdrawn state (see Materials and Methods). Analysis of CPP behavioral scores revealed that bilateral intra-BLA microinfusions of the CaMKII inhibitor KN-62 (50-500 ng/0.5 $\mu \mathrm{l})$ or a specific blocker of CaMKII autophosphorylation (AIP, 50-500 ng/0.5 $\mu \mathrm{l}$ ) dosedependently blocked the acquisition of morphine reward memory, as measured in the CPP paradigm, in rats conditioned in the 
opiate-dependent/withdrawn state. In contrast, intra-BLA ERK1/2 inhibition had no effect on morphine reward memory formation (Fig. 3). For rats receiving intra-BLA KN-62 before morphine reward conditioning, two-way repeatedmeasures ANOVA revealed a significant group by treatment interaction on times spent in saline-paired versus morphinepaired environments $\left(F_{(2,39)}=40.4, p<\right.$ 0.0001). Post hoc analyses revealed that rats treated with $\mathrm{KN}-62$ at the higher dose $(1 \mu \mathrm{g} / 0.5 \mu \mathrm{l} ; n=8)$ demonstrated no significant preference for morphine-paired environments $(p>0.05)$, whereas vehicle control rats $(n=7)$ or rats receiving a lower dose of intra-BLA KN-62 (0.5 $\mu \mathrm{g} /$ $0.5 \mu \mathrm{l} ; n=8$ ) demonstrated robust morphine environment preferences (all $p<$ 0.01; Fig. $3 A$ ). Comparing only time spent in the morphine-paired environments, both vehicle control rats and the low-dose KN-62 group spent significantly more time in morphine-paired environments than those in the high-dose KN-62 group (all $p<0.01$ ).

Given that KN-62 is known to have pharmacological effects nonspecific to CaMKII (Chessell et al., 1998), we performed an additional experiment using AIP, a highly selective CaMKII inhibitor that demonstrates selectivity over the CaMKIV isoform and protein kinases $\mathrm{A}$ and C, and selectively blocks CaMKII autophosphorylation (Ishida et al., 1995). For rats receiving intra-BLA AIP (50-500 $\mathrm{ng} / 0.5 \mu \mathrm{l}$ ) before morphine reward conditioning, two-way ANOVA revealed a significant group by treatment interaction on time spent in saline-paired versus morphine-paired environments $\left(F_{(2,45)}=\right.$

$10.43, p<0.01)$. Post hoc analyses revealed that rats treated with AIP at the higher dose (500 ng/0.5 $\mu \mathrm{l} ; n=8)$ demonstrated no significant preference for morphine-paired environments $(p>$ $0.05)$, whereas vehicle control rats $(n=7)$ or rats receiving a lower dose of intra-BLA AIP ( $50 \mathrm{ng} / 0.5 \mu \mathrm{l} ; n=8)$ demonstrated robust morphine environment preferences (all $p<0.01$; Fig. $3 B$ ).

Given that intra-BLA ERK1/2 inhibition potently blocked morphine reward memory formation in previously opiate-naive rats (Fig. 2), we next examined the effects of intra-BLA ERK inhibition during morphine reward conditioning in the opiatedependent/withdrawn state. Using our previously established behaviorally effective dose of U0126 $(1 \mu \mathrm{g} / 0.5 \mu \mathrm{l})$, we found that intra-BLA MEK inhibition failed to block morphine reward encoding in opiate-dependent/withdrawn rats. Two-way ANOVA revealed a significant group by treatment interaction on time spent in the morphine-paired versus saline-paired environments $\left(F_{(1,23)}=6.5 ; p<0.05\right)$. Post hoc analyses revealed that rats treated with intra-BLA vehicle or the previously established effective dose of intra-BLA UO126 $(1.0 \mu \mathrm{g} / 0.5 \mu \mathrm{l})$ demonstrated robust CPP for morphine-paired environments (all $p<0.01$; Fig. $3 C$ ), indicating that CaMKII signaling, but not ERK1/2 signaling,
Intra-BLA ERK Inhibition Opiate-Naive

saline environment

morphine environment

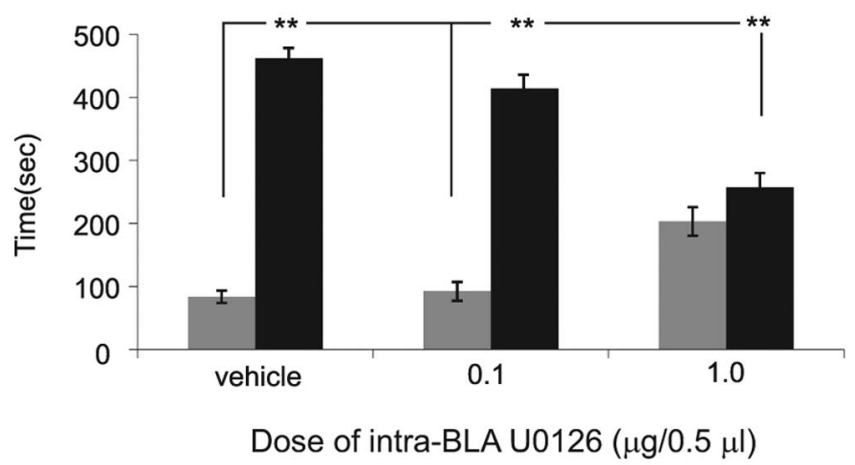

Intra-BLA CaMKII Inhibition Opiate-Naive

saline environment

morphine environment

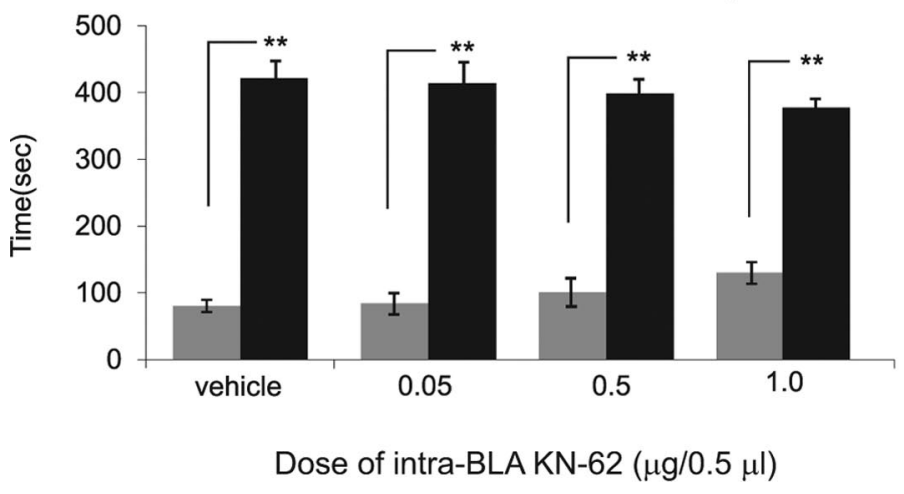

Dose of intra-BLA KN-62 $(\mu \mathrm{g} / 0.5 \mu \mathrm{l})$

Figure 2. Effects of intra-BLA inhibition of ERK versus CaMKII signaling on morphine reward memory acquisition in the opiatemorphine (5 mg/kg, i.p.) CPP in rats trained in a previously opiate-naive state. $\boldsymbol{B}$, In contrast, intra-BLA inhibition of CaMKII signaling with KN-62 failed to block the acquisition of morphine (PP over an order of magnitude dose range $(0.05-1.0 \mu \mathrm{g} / 0.5 \mu \mathrm{l})$. Error bars represent \pm SEM; ${ }^{* *} p<0.01 ;{ }^{*} p<0.05$.

is required for BLA-mediated acquisition of morphine reward memory specifically in the opiate-dependent/withdrawn state.

\section{Intra-BLA inhibition of ERK or CaMKII blocks morphine reward memory acquisition via the VTA}

Given the critical role of VTA inputs to the BLA during opiate reward processing (Ford et al., 2006; Lintas et al., 2011), we next examined whether intra-BLA inhibition of either ERK or CaMKII may modulate the acquisition of morphine CPP via intra-VTA morphine administration. Accordingly, rats received quadruple cannulations within the VTA and BLA (see Materials and Methods) and received a previously established, robustly rewarding dose of intra-VTA morphine (500 ng/0.5 $\mu \mathrm{l}$; Nader and van der Kooy, 1997; Laviolette and van der Kooy, 2004) immediately before intra-BLA microinfusions of our previously established effective doses of U0126 (1.0 $\mu \mathrm{g} / 0.5 \mu \mathrm{l}), \mathrm{KN}-62$ (500 $\mathrm{ng} / 0.5 \mu \mathrm{l})$, or vehicle, in either opiate-naive or dependent/ withdrawn states (Fig. 4). In Figure $4 A$, we present a microphotograph showing a typical intra-VTA bilateral cannulae implantation. In Figure $4 B$, we present a schematic summary of intra-VTA placements from representative experimental groups. For vehicle control rats, two-way ANOVA revealed a significant effect of group on time spent in the morphine-paired versus 


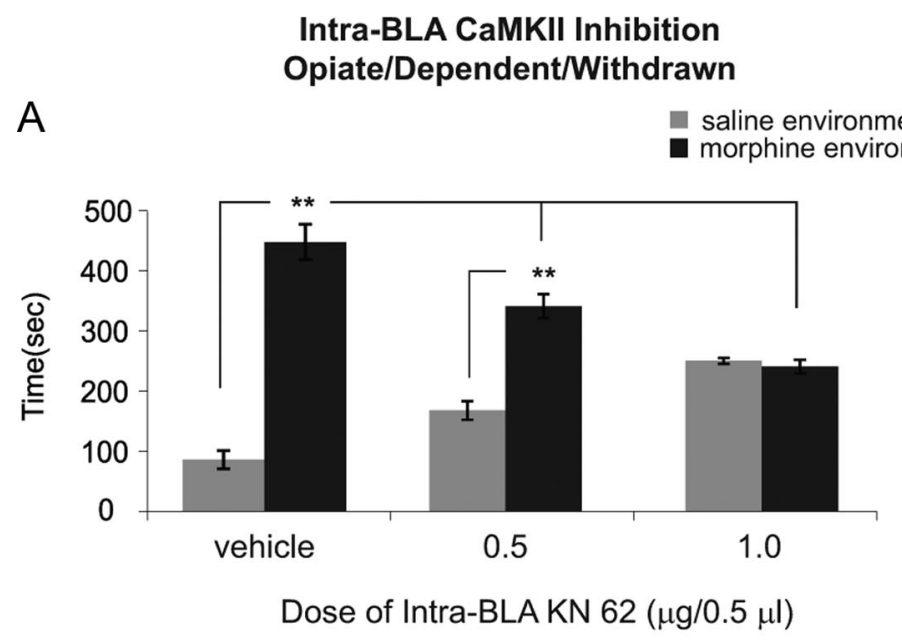

\section{Intra-BLA Blockade of CaMKII Autophosphorylation \\ B Opiate/Dependent/Withdrawn}

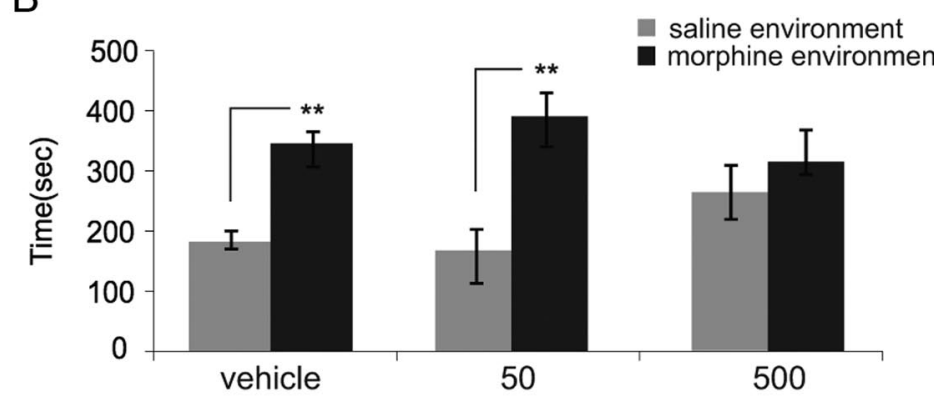

Dose of Intra-BLAAIP $(\mathrm{ng} / 0.5 \mu \mathrm{l})$

\section{Intra-BLA ERK Inhibition Opiate/Dependent/Withdrawn}

C

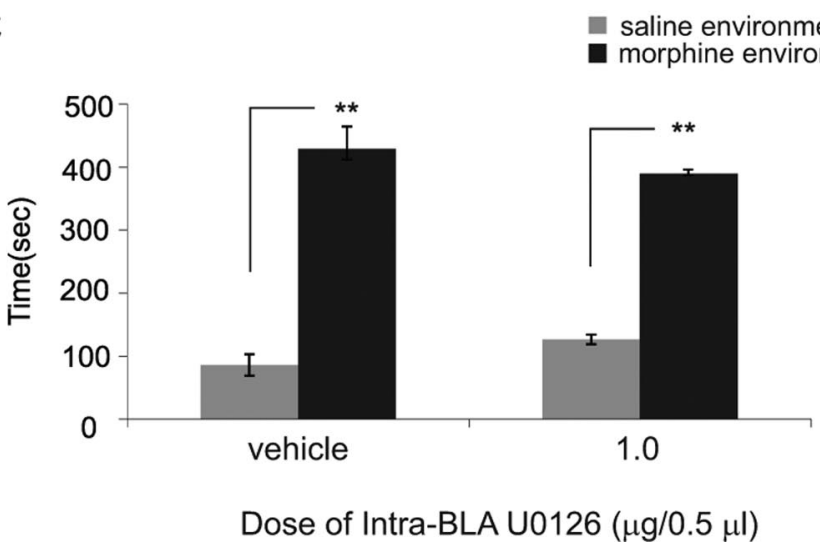

Figure 3. Effects of intra-BLA inhibition of MEK or CaMKII signaling on morphine reward memory acquisition in the opiate-dependent/ withdrawn state. $A$, In contrast to the opiate-naive state, intra-BLA inhibition of CaMKII with KN-62 $(0.5-1.0 \mu \mathrm{g} / 0.5 \mu \mathrm{l})$ dose-dependently blocked the acquisition of morphine ( $5 \mathrm{mg} / \mathrm{kg}$, i.p.) CPP in rats trained in the opiate-dependent/withdrawn state. $B$, Similarly, intra-BLA blockade of CaMKIl autophosphorylation with AIP $(0.05-0.5 \mu \mathrm{g} / 0.5 \mu \mathrm{l})$ dose-dependently blocked the acquisition of morphine CPP in the dependent/withdrawn state. C, In contrast, intra-BLA inhibition of ERK with the previously established effective dose of U0126 $(1.0 \mu \mathrm{g} / 0.5$ $\mu$ l) failed to block the acquisition of morphine CPP in the dependent/withdrawn state.

saline-paired sides $\left(F_{(1,27)}=8.33, p<0.01\right)$. Post hoc analysis revealed that both previously opiate-naive rats $(n=7)$ and rats conditioned in the opiate-dependent/withdrawn state, showed robust CPP for environments paired previously with intra-VTA morphine (all $p<0.01 ; 500 \mathrm{ng} / 0.5 \mu \mathrm{l}$ ), which is consistent with previous reports (Nader and van der Kooy, 1997; Laviolette and van der Kooy, 2004).

For rats receiving the previously established effective dose of intra-BLA U0126 $(1 \mu \mathrm{g} / 0.5 \mu \mathrm{l})$ before intra-VTA morphine, two-way ANOVA revealed a significant group by treatment interaction on time spent in morphine-paired versus salinepaired sides $\left(F_{(1,27)}=21.4, p<0.01\right)$. Post hoc analysis revealed that in previously opiate-naive rats $(n=7)$, similar to effects observed with systemic morphine (Fig. 2), intra-BLA ERK inhibition blocked the acquisition of morphine CPP $(p>0.05)$. However, for rats conditioned in an opiatedependent/withdrawn state $(n=7)$, intraBLA ERK inhibition failed to block the acquisition for intra-VTA morphine reward $\mathrm{CPP}$, with rats showing robust CPP for environments paired with intra-VTA morphine (500 ng/0.5 $\mu \mathrm{l} ; p<0.01$; Fig. $4 D$ ). Furthermore, comparing time spent in morphine-paired environments alone revealed that the opiate-dependent/withdrawn rats spent more time in morphinepaired environments than the previously opiate-naive rats $(p<0.05)$.

For rats receiving the previously established highest effective dose of intra-BLA $\mathrm{KN}-62(1 \mu \mathrm{g} / 0.5 \mu \mathrm{l})$ before intra-VTA morphine, two-way ANOVA revealed a significant group by treatment interaction on time spent in the morphine-paired versus the saline-paired side $\left(F_{(1,27)}=\right.$ $24.9, p<0.01)$. Post hoc analysis revealed that in previously opiate-naive rats $(n=$ 7 ), similar to effects observed with systemic morphine (Fig. 2), intra-BLA $\mathrm{KN}-62$ failed to block the acquisition of intra-VTA morphine CPP $(p>0.05)$. However, for rats conditioned in an opiate-dependent/withdrawn state $(n=7)$, intra-BLA KN-62 completely blocked morphine CPP for intra-VTA morphine ( $500 \mathrm{ng} / 0.5 \mu \mathrm{l} ; p>0.05$; Fig. $4 E$ ). Furthermore, comparing time spent in morphine-paired environments alone revealed that the opiate-dependent/withdrawn rats spent more time in morphine-paired environments than the previously opiatenaive rats $(p<0.05)$.

Intra-BLA DA D1 receptor modulation of opiate reward memory is linked to an ERK-dependent signaling substrate In the opiate-naive state, activation of intra-

BLA D1-like receptors strongly potentiates the rewarding effects of opiates and increases neuronal response sensitivity to opiate administration in neurons of the NAc (Lintas et al., 2011). To examine whether intra-BLA ERK signaling may modulate opiate reward processing through a D1R-dependent substrate, and demonstrate a potential functional link between intra-BLA D1 


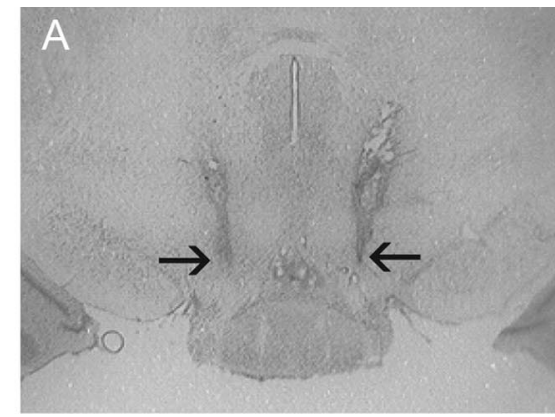

\section{Vehicle Controls: Intra-VTA Morphine} $(500 \mathrm{ng} / 05 \mu \mathrm{l})$

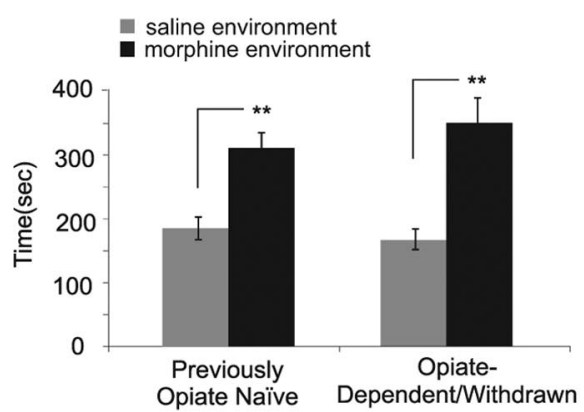

$\mathrm{B}$

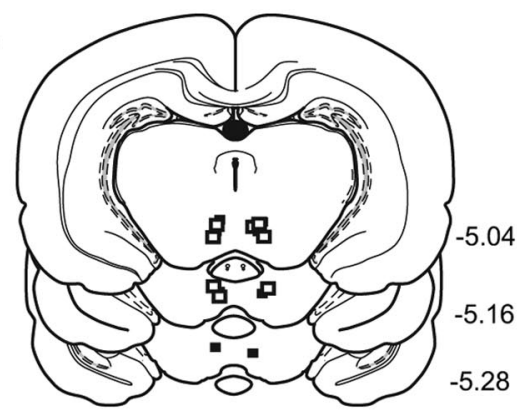

D Intra-BLA ERK Inhibition (U0126 $1.0 \mathrm{ug} / 0.5 \mu \mathrm{ll}$ VTA Morphine (500 $\mathrm{ng} / 0.5 \mu \mathrm{l})$

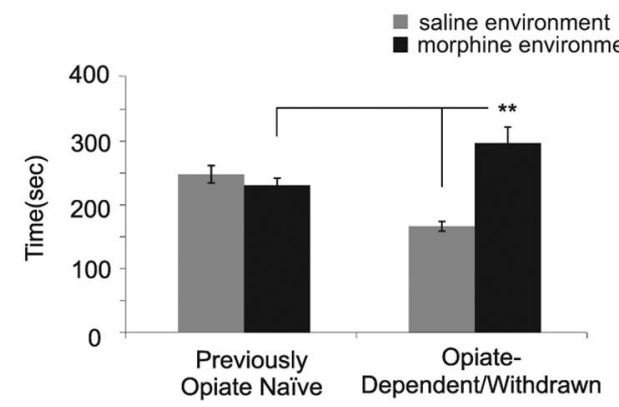

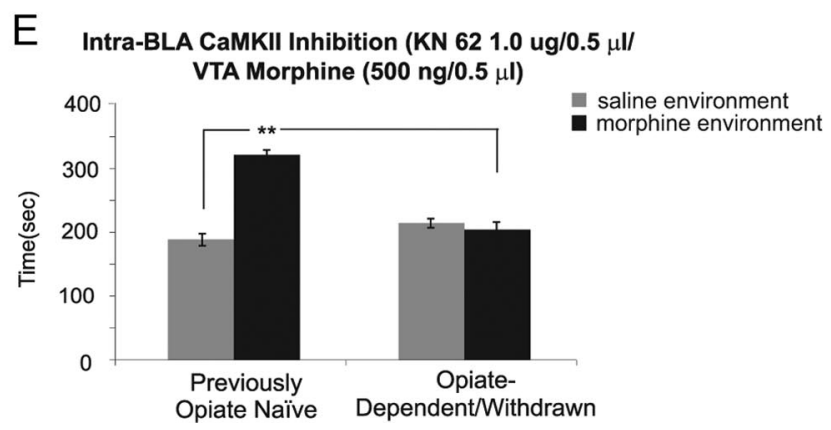

Figure 4. Effects of intra-BLA MEK or CaMKII inhibition on intra-VTA opiate reward processing. A, Microphotograph depiction of a representative bilateral intra-VTA guide cannula and injector tip placement. $\boldsymbol{B}$, Schematic depiction of representative bilateral intra-VTA injector tip placements. $\boldsymbol{\square}$, Previously opiate-naive rats receiving intra-VTA morphine $(0.5 \mu \mathrm{g} / 0.5 \mu \mathrm{l})$; $\square$, opiatedependent/withdrawn rats receiving intra-VTA morphine $(0.5 \mu \mathrm{g} / 0.5 \mu \mathrm{l})$. C, Intra-VTA morphine microinfusions $(500 \mathrm{ng} / 0.5 \mathrm{ml})$ produce robust (PP in both previously opiate-naive and dependent/withdrawn experimental groups. $\boldsymbol{D}$, Intra-BLA microinfusions of the previously established effective dose of the ERK inhibitor U0126 (1.0 $\mu \mathrm{g} / 0.5 \mu \mathrm{l})$ completely blocked the rewarding effects of intra-VTA morphine only in the opiate-naive exposure state. $\boldsymbol{E}$, In contrast, intra-BLA inhibition of CaMKII with the previously established effective dose of KN-62 (1.0 $\mu \mathrm{g} / 0.5 \mu$ l) completely blocked intra-VTA morphine reward CPP only in the opiate-dependent/withdrawn exposure state.

receptor-mediated modulation of opiate reward signaling, we examined the effects of intra-BLA ERK inhibition on D1 receptormediated potentiation of opiate reward signals (Fig. 5). For this experiment, four experimental groups in the opiate-naive state were included. Before CPP conditioning with a subreward threshold dose of morphine ( $0.05 \mathrm{mg} / \mathrm{kg}$, i.p.), Group 1 received intra-BLA vehicle $(n=7)$. Group 2 received intra-BLA SKF 81297, using a concentration $(1.0 \mu \mathrm{g} / 0.5 \mu \mathrm{l})$ that we have previously demonstrated to effectively potentiate the rewarding properties of subthreshold morphine ( $n=8$; Lintas et al., 2011). Group 3 received intra-BLA SKF 81297 $(1.0 \mu \mathrm{g} / 0.5 \mu \mathrm{l})$ coadministered with our previously established effective dose of U0126 $(1.0 \mu \mathrm{g} / 0.5 \mu \mathrm{l})$. Finally, Group 4 received intra-BLA SKF $81297(1.0 \mu \mathrm{g} / 0.5 \mu \mathrm{l})$ coadministered with our previously established effective dose of $\mathrm{KN} 62(1 \mu \mathrm{g} / 0.5 \mu \mathrm{l} ; n=7)$. Analysis of CPP test scores with two-way ANOVA revealed a significant interaction between treatment group and time spent in salinepaired versus morphine-paired environments during testing $\left(F_{(3,59)}=8.23 ; p<0.001\right)$. Post hoc analysis revealed that, similar to previous findings, vehicle control rats display no CPP for environ- ments paired with this subthreshold conditioning dose of morphine $(0.05 \mathrm{mg} / \mathrm{kg}$, i.p., $p>0.05)$. In contrast, for rats receiving intra-BLA D1 receptor activation with SKF $81297(1.0 \mu \mathrm{g} / 0.5 \mu \mathrm{l})$, a robust morphine CPP is demonstrated $(p<0.01)$. While coadministration of the ERK inhibitor U0126 $(1.0 \mu \mathrm{g} / 0.5 \mu \mathrm{l})$ completely blocked the ability of D1 receptor activation to potentiate subreward threshold morphine reward $(p>0.05)$, coadministration with the CaMKII inhibitor KN-62 $(1.0 \mu \mathrm{g} / 0.5 \mu \mathrm{l})$ had no effect on intra-BLA D1 receptor-mediated morphine-reward potentiation, with these rats demonstrating a robust morphine $\operatorname{CPP}(p<0.01$; Fig. $5 A)$. Thus, in the opiate-naive state, intra-BLA D1 receptor-mediated modulation of opiate reward memory acquisition depends upon an ERK signaling pathway, but not a CaMKII-dependent pathway.

Intra-BLA DA D2 receptor modulation of opiate reward memory is linked to a CaMKII-dependent mechanism In the opiate-dependent/withdrawn state, activation of intraBLA DA D2 receptors strongly potentiates the rewarding effects of opiates and increases neuronal response sensitivity to opiate 


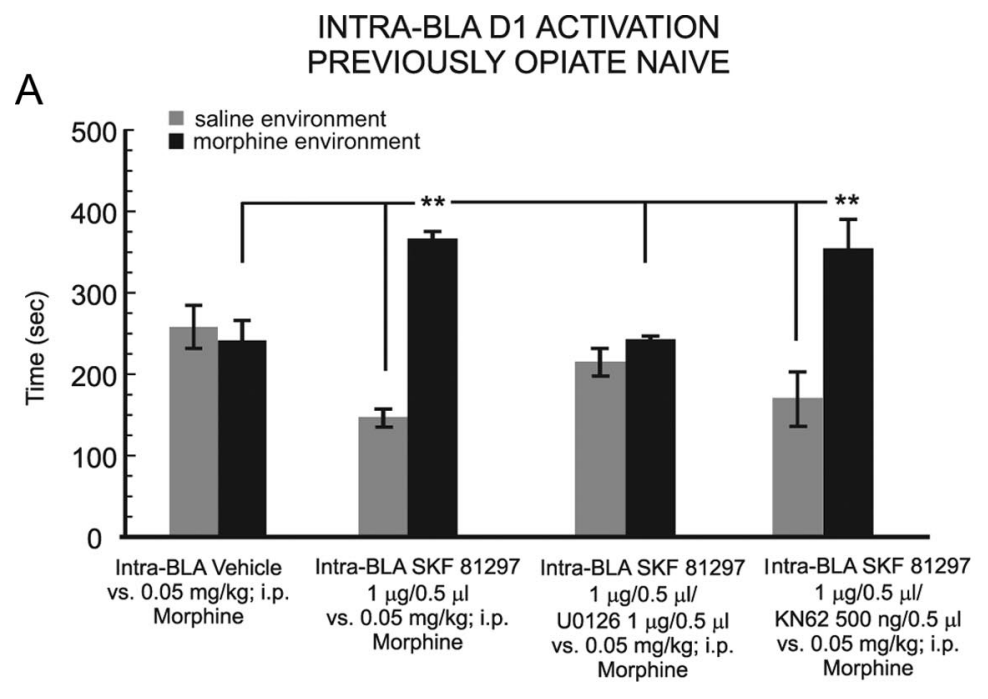

B OPIATE DEPENDENT/WITHDRAWN

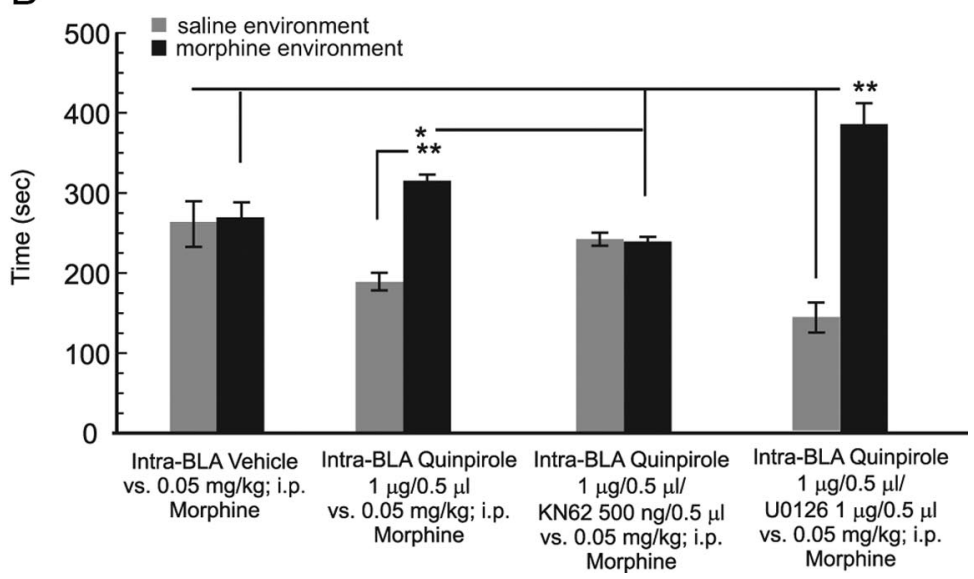

Figure 5. Intra-BLA DA receptor modulation of morphine reward salience is functionally dissociated through ERK and CaMKII signaling pathways as a function of opiate-exposure state. A, For intra-BLA vehicle controls, a subthreshold conditioning dose of morphine $(0.05 \mathrm{mg} / \mathrm{kg}$, i.p.) fails to produce a CPP. However, for rats receiving a previously established effective dose of the D1 receptor agonist SKF $81297(1.0 \mu \mathrm{g} / 0.5 \mu \mathrm{l})$, this dose of morphine now produces robust CPP. Coadministration of the ERK inhibitor U0126 $(1.0 \mu \mathrm{g} / 0.5 \mu \mathrm{l})$ completely blocked the ability of D1 receptor activation to potentiate subreward threshold morphine, whereas coadministration of the CaMKII inhibitor KN-62 (1.0 $\mu \mathrm{g} / 0.5 \mu \mathrm{l})$ failed to block the reward-potentiating effects of intraBLA D1 receptor activation. $B$, In contrast, in the opiate-dependent/withdrawn state, for intra-BLA vehicle controls, a subthreshold conditioning dose of morphine $(0.05 \mathrm{mg} / \mathrm{kg}$, i.p.) fails to produce a CPP. However, rats receiving a previously established effective dose of the $\mathrm{D} 2$ receptor agonist quinpirole $(1.0 \mu \mathrm{g} / 0.5 \mu \mathrm{l})$, this dose of morphine now produces robust CPP. Coadministration of the CaMKII inhibitor KN-62 $(1.0 \mu \mathrm{g} / 0.5 \mu \mathrm{l})$ completely blocked the ability of D2 receptor activation to potentiate subreward threshold morphine, whereas coadministration of the ERK inhibitor U0126 $(1.0 \mu \mathrm{g} / 0.5 \mu \mathrm{l})$ failed to block the reward-potentiating effects of intra-BLA D2 in the dependent/withdrawn state.

administration in neurons of the NAc (Lintas et al., 2011). To examine whether intra-BLA CaMKII signaling may modulate opiate reward processing through a D2R-dependent substrate, and demonstrate a potential functional link between intra-BLA $\mathrm{D} 2$ receptor-mediated modulation of opiate reward signaling, we examined the effects of intra-BLA CaMKII inhibition on D2 receptor-mediated potentiation of opiate reward signals (Fig. 5). For this experiment, four experimental groups in the opiate-dependent/withdrawn state (see Materials and Methods) were included. Before CPP conditioning with a subreward threshold dose of morphine $(0.05 \mathrm{mg} / \mathrm{kg}$, i.p.), Group 1 received intra-BLA vehicle $(n=7)$. Group 2 received the $\mathrm{D} 2$ receptor agonist quinpirole using a concentration $(1.0 \mu \mathrm{g} / 0.5 \mu \mathrm{l})$ that we have previously demonstrated to effectively potentiate the rewarding properties of subthreshold morphine in the opiate-dependent/withdrawn state $(n=7$; Lintas et al., 2011). Group 3 received intra-BLA quinpirole $(1.0 \mu \mathrm{g} / 0.5$ $\mu \mathrm{l})$ coadministered with our previously established, highest effective dose of the CaMKII inhibitor KN-62 $(n=8,1.0 \mu \mathrm{g} /$ $0.5 \mu \mathrm{l})$. Finally, Group 4 received intraBLA quinpirole $(1.0 \mu \mathrm{g} / 0.5 \mu \mathrm{l})$ coadministered with our previously established effective dose of the ERK inhibitor U0126 $(1 \mu \mathrm{g} / 0.5 \mu \mathrm{l} ; n=7)$. Analysis of CPP test scores with two-way ANOVA revealed a significant interaction between treatment group and time spent in saline-paired versus morphine-paired environments during testing $\left(F_{(3,57)}=12.86 ; p<0.0001\right)$. Post hoc analysis revealed that, similar to previous findings, vehicle control rats display no CPP for environments paired with this subthreshold conditioning dose of morphine $(0.05 \mathrm{mg} / \mathrm{kg}$, i.p., $p>0.05)$. In contrast, for rats receiving intra-BLA quinpirole $(1.0 \mu \mathrm{g} / 0.5 \mu \mathrm{l})$, a robust morphine CPP is demonstrated $(p<0.01)$, which is consistent with previous findings (Lintas et al., 2011). While coadministration of the CaMKII inhibitor KN-62 (1.0 $\mu \mathrm{g} / 0.5 \mu \mathrm{l})$ completely blocked the ability of D2 receptor activation to potentiate subreward threshold morphine reward $(p>0.05)$, coadministration with the ERK inhibitor U0126 $(1.0 \mu \mathrm{g} / 0.5 \mu \mathrm{l})$ had no effect, with these rats demonstrating a robust morphine CPP ( $p<0.01$; Fig. $5 B)$. Thus, in direct contrast to previously opiate-naive experimental groups, intraBLA D2 receptor-mediated modulation of opiate reward memory acquisition depends upon a CaMKII signaling pathway, independently of ERK.

\section{Effects of opiate dependence and withdrawal on intra-BLA protein expression levels of CaMKII $\alpha$, CaMKII $\beta$, and ERK1/2}

Thus far, behavioral results have demonstrated a functional double dissociation in the processing of opiate-related reward memory between the previously opiate-naive versus dependent/ withdrawn states, with an ERK-dependent signaling substrate dominant in the naive state, followed by a switch to a CaMKII $\alpha$ dependent substrate in the dependent/withdrawn states. Therefore, we next examined protein expression levels of ERK1/2 or CaMKII $\alpha$, comparing both total and phosphorylated levels of these molecules in either previously opiate-naive rats $(n=7)$ or rats treated with chronic opiates and sampled at $21 \mathrm{~h}$ of postopiate withdrawal ( $n=7$; see Materials and Methods). Our analyses revealed that opiate exposure and withdrawal induces significant alterations in the dynamics of both ERK1/2 and CaMKII $\alpha$ levels across opiate-exposure states (Figs. 6,7). We first compared total ERK1 and ERK2 levels across opiate-naive versus opiate-dependent/withdrawn groups. Analysis of total amygdala expression 


\section{A}
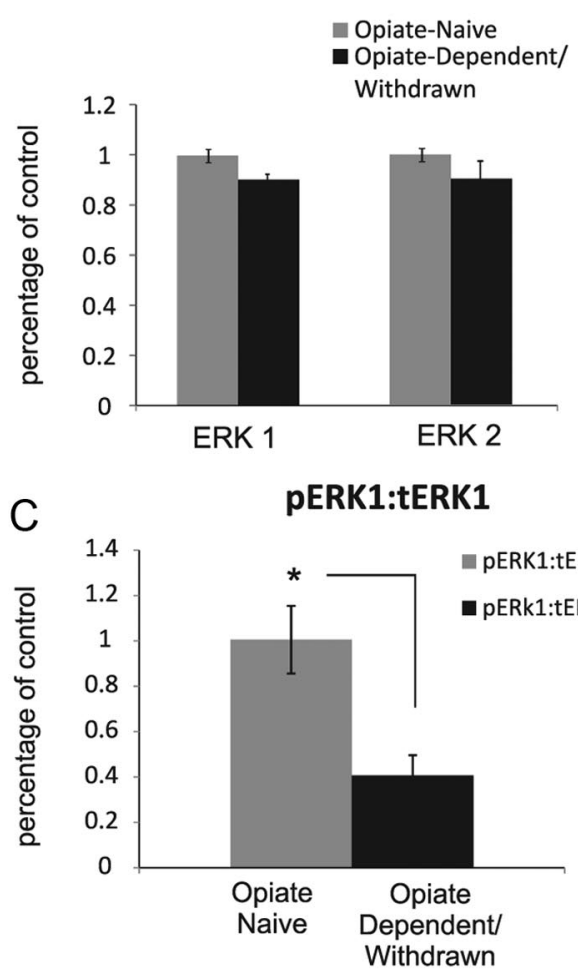

B Total BLA pERK $1 / 2$
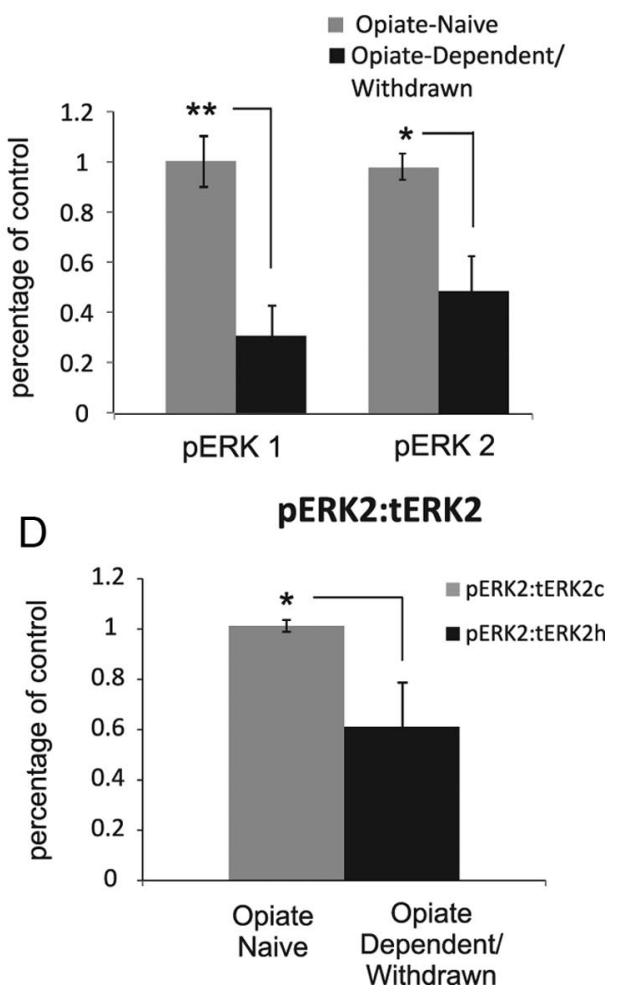

Figure 6. Effects of chronic opiate exposure and withdrawal on total and phosphorylated ERK1/2 protein expression levels in amygdala. $\boldsymbol{A}$, Western blot analysis of total amygdalar levels of ERK1 and ERK2 expression revealed no difference in total ERK1 or ERK2 levels in either opiate-naive or opiate-dependent/withdrawn samples. $\boldsymbol{B}$, In contrast, total pERK1 and pERK2 levels were significantly downregulated across naive versus dependent/withdrawn samples. C, $\boldsymbol{D}$, Comparing $\mathrm{pERK} 1 / 2$ to total ERK1/2 ratios reveals a significant downregulation in relative $\mathrm{pERK} 1 / 2$ versus total ERK1/2 levels.

levels of ERK1 or ERK2 revealed no significant differences between opiate-naive control rats versus opiate-dependent/withdrawn rats (Fig. $\left.6 A, F_{(1,27)}=0.52 ; p>0.05\right)$. Next, comparing levels of phosphorylated ERK1/2 (pERK1/2) revealed a significant effect of treatment group (opiate-naive vs dependent/withdrawn) on total amygdala expression levels of pERK1/2 (Fig. $6 B$; $\left.F_{(1,27)}=26.7 ; p<0.001\right)$. Finally, comparing the pERK/ERK expression ratios revealed significant downregulation of both pERK1 $\left(t_{(12)}=3.23 ; p<0.01\right)$ and $2\left(t_{(12)}=2.37 ; p<0.05\right)$ in opiate-dependent/withdrawn groups relative to previously opiate-naive rats (Fig. 6C,D). Sample Western blot expression patterns, presented in Figure $7 A, B$, show representative ERK1/2 total and pERK1/2 levels across opiate-exposure groups. Western blot analyses of the density of protein expression of total CaMKII $\alpha$ and phosphorylated CaMKII $\alpha$ (pCaMKII $\alpha$ ) across previously opiate-naive $(n=7)$ versus dependent/withdrawn rats $(n=7)$ revealed a dramatic decrease in both total and phosphorylated levels of CaMKII $\alpha$. This attenuation in CaMKII $\alpha$ signaling was so profound that quantification of protein levels in the opiate-dependent/withdrawn groups was not possible within the linear range of the film nor could a band be detected in the test lanes even with substantial overexposure of the control lanes. To determine whether opiate dependence and withdrawal induced changes in CaMKII isoforms beyond $\mathrm{CaMKII} \alpha$, we ran a second analysis comparing levels of the CaMKII $\beta$ isoform across opiatenaive versus dependent/withdrawn states (see Materials and Methods). In contrast to the effects observed on total CaMKII $\alpha$ protein levels, total levels of CaMKII $\beta$ were slightly, but not significantly, elevated in the opiate-naive versus dependent/withdrawn states. Analysis of total amygdala relative to expression levels of CaMKII $\beta$, revealed no significant differences between opiate-naive control rats versus opiate-dependent/withdrawn rats (Fig. $\left.7 D, E ; t_{(5)}=1.25 ; p>0.05\right)$.

\section{Discussion}

The present results demonstrate a molecular memory switch within the BLA controlled by opiate-exposure state. While the formation of systemic or intra-VTA-mediated opiate reward memories is sensitive to intra-BLA ERK inhibition exclusively during the acute opiate-exposure state, following opiate exposure and withdrawal, opiate memory formation switches to a CaMKII-sensitive memory mechanism. Furthermore, opiate exposure and withdrawal causes significant downregulation of intra-amygdalar pERK1/2 and a dramatic downregulation of total and phosphorylated levels of CaMKII $\alpha$, but no significant effects on CaMKII $\beta$ levels. In addition, our behavioral evidence links intra-BLA D1 versus D2 receptor-mediated modulation of opiate reward salience to dissociable ERK versus CaMKII signaling pathways, further suggesting functional divergence between a D1 receptor-mediated, ERK-sensitive memory pathway versus a D2 receptor-mediated, CaMKII-sensitive memory mechanism, regulated by opiate-exposure state.

\section{Intra-BLA ERK1/2 signaling and acute opiate reward memory formation}

Considerable evidence links ERK phosphorylation events to memory-related processes. Spatial and reward-related memory acquisition involves pERK upregulation, whereas inhibition of ERK phosphorylation leads to impairments in acute memory formation (Kelly et al., 2003; Alvarez-Jaimes et al., 2005; Fricks- 
A
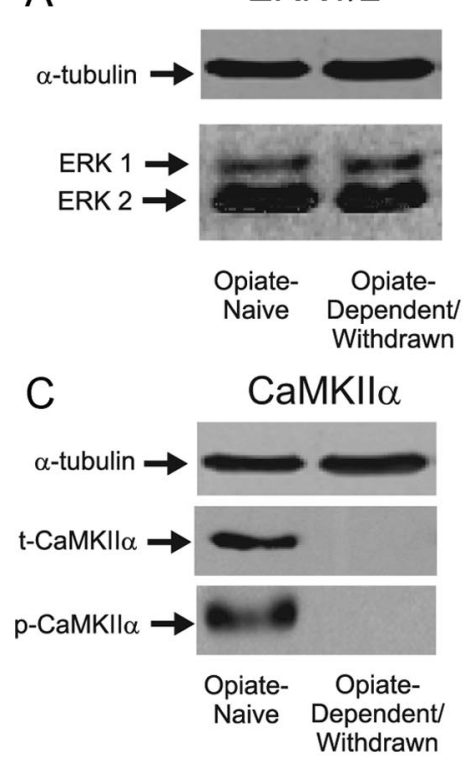

E
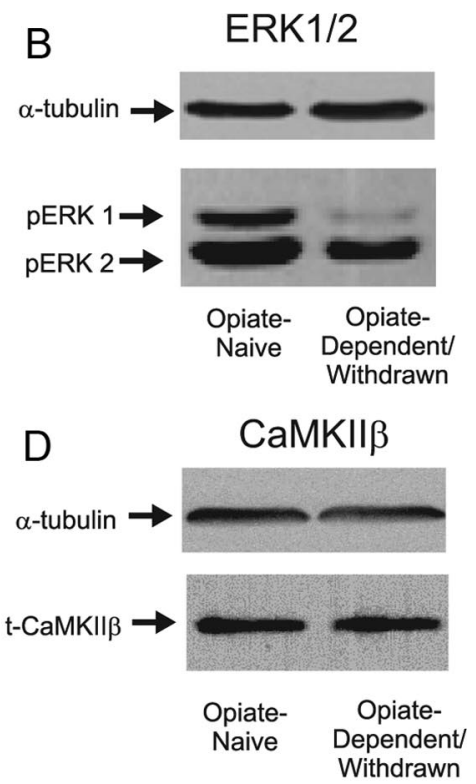

Total BLA CaMKII $\beta$

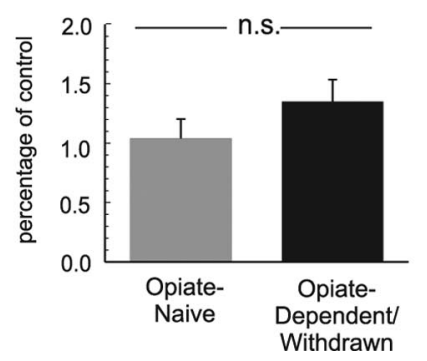

Figure 7. Effects of chronic opiate exposure and withdrawal on ERK1/2 and CaMKIl $\alpha$ signaling within the amygdala. $\boldsymbol{A}$, Representative Western blot comparing total ERK1 and ERK2 levels across opiate-naive versus dependent/withdrawn experimental groups. $\boldsymbol{B}$, Representative Western blot comparing pERK1 and pERK2 levels across opiate-exposure groups. $\boldsymbol{C}$, Representative Western blot demonstrating dramatic downregulation of both total and phosphorylated levels of CaMKIl $\alpha$ across opiate-exposure groups. D, Representative Western blot demonstrating levels of total intra-BLA CaMKII $\beta$ in either opiate-naive or opiate-dependent/withdrawn rats. $\boldsymbol{E}$, Total levels of intra-BLA CaMKIII $\beta$ do not show significant differences between experimental opiateexposure states.

Gleason and Marshall, 2011). Exposure to opiates potently modulates total and phosphorylated ERK expression levels in various neural regions. However, the effects of chronic opiate exposure upon ERK1/2 signaling within the BLA have not previously been characterized. Muller and Unterwald (2004) have reported that acute or long-term morphine exposure causes a reduction in pERK, specifically within the NAc. Furthermore, exposure to various psychostimulants acutely increase pERK levels across several neural regions (Ferrer-Alcón et al., 2004; Seo et al., 2008; Ibba et al., 2009; Fricks-Gleason and Marshall, 2011; Ma et al., 2001; Acquas et al., 2010). Interestingly, blockade of D1Rs can prevent drug exposure-induced increases in pERK levels (Ibba et al., 2009; Acquas et al., 2010; Fricks-Gleason and Marshall, 2011; Li et al., 2011), suggesting critical functional links between D1R transmission and ERK phosphorylation events.

In terms of ERK's role during associative memory formation, ERK signaling may serve as a coincidence detector between DAergic and glutamatergic (GLUTergic) inputs to neural regions involved in associative memory formation (Valjent et al., 2005; Girault et al., 2007). Previous research has reported intra-BLA functional convergence between GLUTergic inputs from sensory cortical regions with DAergic inputs during associative process-

ing in BLA neuronal populations (Rosenkranz and Grace, 2001, 2003). In the present study, we found that intra-BLA inhibition of ERK signaling was ineffective in blocking opiate-related associative memory, specifically in the opiate-dependent/withdrawn state. This behavioral effect was concomitant with an observed reduction in phosphorylated, but not total, ERK1/2 levels within the BLA. While further studies are required to elucidate the precise mechanism(s) whereby opiate exposure and withdrawal leads to these behavioral and molecular adaptations, one possibility is that the functional switch from a D1 receptor-dependent to a D2 receptor-dependent signaling substrate within the BLA (Lintas et al., 2011, 2012) may be linked to these observations. Thus, in the present study, we observed a functional relationship between intraBLA D1 receptor activation and ERK (but not CaMKII signaling) in the ability of intra-BLA DA receptor activation to potentiate the reward salience of opiate conditioning behaviors (Fig. 5). In addition, we have reported previously that intraBLA D1 receptor activation or blockade only modulates opiate reward memory formation in the opiate-naive state (Lintas et al., 2012). Furthermore, previous evidence has demonstrated a profound reduction in intra-BLA D1 receptor levels following chronic opiate exposure (Bhargava and Gulati, 1990). Together, this evidence may suggest that chronic opiate exposure and the resulting downregulation in intra-BLA D1 receptor substrates linked to ERK1/2 signaling may render the inhibition of either D1 or ERK signaling ineffective in modulating opiaterelated memory processing during opiate dependence and withdrawal. Alternatively, a shift in the functional balance between CaMKII versus ERK1/2 signaling substrates following chronic opiate exposure may lead to the observed switch between these mechanisms, such that a CaMKII-dependent memory mechanism may overshadow the functional role of ERK signaling specifically following chronic opiate exposure and withdrawal.

Chronic opiate exposure and withdrawal switches intra-BLA opiate reward memory processing to a CaMKII-sensitive memory substrate

The phosphorylation cascade of CaMKII $\alpha$ leads to a variety of modifications in neuronal function linked to associative memory acquisition (Shen and Meyer, 1999; Frankland et al., 2001; Lisman et al., 2002). Thus, pCaMKII $\alpha$ levels are elevated during the formation of new memories while blockade of CaMKII impairs memory formation (Fan et al., 1999; Narita et al., 2004; Lauzon et al., 2012). In addition, CaMKII signaling is closely associated with the activation of D2Rs and D2R activation leads to increased downstream CaMKII levels (Liu et al., 2009; Gu and Yan, 2004; Novak and Seeman, 2010). In addition to the CaMKII $\alpha$ isoform, other forms of CaMKII, such as CaMKII $\beta$, play a role in learning- 
related and memory-related neural plasticity processes (Moriya et al., 2000; Cho et al., 2007). We report that pharmacological blockade of CaMKII or CaMKII autophosphorylation blocked the acquisition of opiate-related reward memories after chronic exposure to opiates and withdrawal. This effect was associated with a dramatic reduction in total CaMKII $\alpha$ levels within the amygdala following chronic opiate exposure. In contrast, we observed no significant changes in total CaMKII $\beta$ levels across exposure states.

Several potential mechanisms may account for the observed shift to an intra-BLA, D2R-mediated CaMKII-dependent memory substrate. For example, previous reports have demonstrated that chronic psychostimulant exposure can modulate CaMKII levels across various neural regions (Lou et al., 1999; Wang and Wang, 2006; Zhong et al., 2006; Greenstein et al., 2007; Papaleo et al., 2012). Modulation of CaMKII levels via opiate exposure appears to be bidirectional. Thus, whereas acute opiate exposure frees $\mathrm{Ca}^{2+}$ from intracellular cystolic stores and increases pCaMKII levels for a short period of time, chronic exposure induces a longer-lasting upregulation of pCaMKII levels in various neural regions (Fan et al., 1999; Lou et al., 1999; Wang and Wang, 2006; Greenstein et al., 2007; Seo et al., 2008; Wang et al., 2011). Chronic drug exposure is associated with a decrease in pCaMKII levels (Lou et al., 1999; Lu et al., 2000; Lisman et al., 2002; Wanjerkhede and Bapi, 2008; Christian et al., 2012) and inhibition of amygdalar CaMKII attenuates behavioral signs of morphine dependence (Lu et al., 2000). Interestingly, chronic treatment with methadone or morphine has been shown to dramatically decrease CaMKII levels in hippocampal and frontal cortical regions in rat brain (Andersen et al., 2012), demonstrating a functional link between chronic opiate exposure and CaMKII regulation.

Behaviorally, several lines of evidence suggest a switch to a D2R-sensitive state following chronic opiate exposure. We have reported previously that within the BLA, the acquisition of opiate reward memory depends upon a D2 receptor-dependent substrate only in the opiate-dependent/withdrawn state (Lintas et al., 2011, 2012). In these cases, intra-BLA D2R transmission bidirectionally modulated opiate reward memory processing such that D2R blockade prevented the acquisition of opiate-related reward memory and attenuated neuronal sensitivity to opiate administration in NAc shell (NAshell) neuronal populations. Conversely, D2R activation caused a strong potentiation in behavioral sensitivity to the rewarding effects of opiates, concomitant with increased NAshell neuronal sensitivity to opiates (Lintas et al., 2012). Furthermore, chronic opiate exposure leads to a generalized D2R sensitization state manifest by hypersensitivity to the behavioral activation effects of D2 receptor agonists (Druhan et al., 2000). Given previous molecular evidence demonstrating that activation of $\mathrm{D} 2 \mathrm{R}$ transmission causes a strong attenuation in calcium $\left(\mathrm{Ca}^{2+}\right)$ levels (Bigornia et al., 1990; Lee, 1996; Hernandez-Lopez et al., 2000), this may suggest that a state linked to D2-receptor overstimulation may result in attenuated CaMKII levels linked to intracellular $\mathrm{Ca}^{2+}$ downregulation. In this case, severely depleted CaMKII levels within the BLA in the opiatedependent/withdrawn state would render CaMKII memory processing substrates highly susceptible to any further, pharmacologically induced attenuation of the remaining CaMKII $\alpha$ stores, which is consistent with the present behavioral findings. An alternative possibility is that other isoforms of CaMKII, such as CaMKII $\beta$, may become necessary for opiate reward memory formation specifically during states of chronic opiate exposure and withdrawal. Indeed, previous evidence demonstrates the involvement of both $\alpha$ and $\beta$ CaMKII isoforms during amygdala- mediated memory formation (Moriya et al., 2000). In the present study, we observed no significant alteration in intra-BLA CaMKII $\beta$ levels across opiate-exposure states. Given that currently available pharmacological inhibitors of CaMKII do not discriminate between these isoforms, it is possible that the observed block of opiate reward memory may have been mediated through CaMKII $\beta$ substrates. Nevertheless, future studies are required to more closely examine these possibilities.

\section{Conclusions}

The present findings reveal a novel memory plasticity mechanism within the amygdala, controlled by opiate-exposure state. While future studies are required to precisely characterize the functional and anatomical links between intra-BLA ERK1/2 and CaMKII $\alpha$ opiate-related memory signaling events with D1R versus D2R receptor substrates, the present findings demonstrate that opiaterelated reward memory formation within the BLA uses two distinct molecular pathways during the acute versus dependent and withdrawn opiate-exposure states. These results have critical implications for understanding how the dependent versus nondependent brain may process drug-reward-related associative memories through distinct intra-amygdalar memory pathways.

\section{References}

Acquas E, Vinci S, Ibba F, Spiga S, De Luca MA, Di Chiara G (2010) Role of dopamine D1 receptors in caffeine-mediated ERK phosphorylation in the rat brain. Synapse 64:341-349. CrossRef Medline

Alvarez-Jaimes L, Feliciano-Rivera M, Centeno-González M, MaldonadoVlaar CS (2005) Contributions of the mitogen-activated protein kinase and protein kinase $\mathrm{C}$ cascades in spatial learning and memory mediated by the nucleus accumbens. J Pharmacol Exp Ther 314:1144-1157. CrossRef Medline

Andersen JM, Klykken C, Mørland J (2012) Long-term methadone treatment reduces phosphorylation of CaMKII in rat brain. J Pharm Pharmacol 64:843-847. CrossRef Medline

Bhargava HN, Gulati A (1990) Modification of brain and spinal cord dopamine D1 receptors labeled with [3H]SCH 23390 after morphine withdrawal from tolerant and physically dependent rats. J Pharmacol Exp Ther 252:901-907. Medline

Bigornia L, Allen CN, Jan CR, Lyon RA, Titeler M, Schneider AS (1990) D2 dopamine receptors modulate calcium channel currents and catecholamine secretion in bovine adrenal chromaffin cells. J Pharmacol Exp Ther 252:586-592. Medline

Bishop SF, Lauzon NM, Bechard M, Gholizadeh S, Laviolette SR (2011) NMDA receptor hypofunction in the prelimbic cortex increases sensitivity to the rewarding properties of opiates via dopaminergic and amygdalar substrates. Cereb Cortex 21:68-80. CrossRef Medline

Bissière S, Humeau Y, Lüthi A (2003) Dopamine gates LTP induction in lateral amygdala by suppressing feedforward inhibition. Nat Neurosci 6:587-592. CrossRef Medline

Chessell IP, Michel AD, Humphrey PP (1998) Effects of antagonists at the human recombinant P2X7 receptor. Br J Pharmacol 124:1314-1320. CrossRef Medline

Cho MH, Cao X, Wang D, Tsien JZ (2007) Dentate gyrus-specific manipulation of $\beta-\mathrm{Ca}^{2+} /$ calmodulin-dependent kinase II disrupts memory consolidation. Proc Natl Acad Sci U S A 104:16317-16322. CrossRef Medline

Christian DT, Alexander NJ, Diaz MR, Robinson S, McCool BA (2012) Chronic intermittent ethanol and withdrawal differentially modulate basolateral amygdala AMPA-type glutamate receptor function and trafficking. Neuropharmacology 62:2430-2439. CrossRef Medline

De Jaeger X, Bishop SF, Ahmad T, Lyons D, Ng GA, Laviolette SR (2013) The effects of AMPA receptor blockade in the prelimbic cortex on systemic and ventral tegmental area opiate reward sensitivity. Psychopharmacology 225:687-695. CrossRef Medline

Druhan JP, Walters CL, Aston-Jones G (2000) Behavioral activation induced by D2-like receptor stimulation during opiate withdrawal. J Pharmacol Exp Ther 294:531-538. Medline

Fan GH, Wang LZ, Qiu HC, Ma L, Pei G (1999) Inhibition of calcium/ 
calmodulin-dependent protein kinase II in rat hippocampus attenuates morphine tolerance and dependence. Mol Pharmacol 56:39-45. Medline

Ferrer-Alcón M, García-Fuster MJ, La Harpe R, García-Sevilla JA (2004) Long-term regulation of signaling components of adenylyl cyclase and mitogen-activated protein kinase in the pre-frontal cortex of human opiate addicts. J Neurochem 90:220-230. CrossRef Medline

Floresco SB, Yang CR, Phillips AG, Blaha CD (1998) Basolateral amygdala stimulation evokes glutamate receptor-dependent dopamine efflux in the nucleus accumbens of the anaesthetized rat. Eur J Neurosci 10:12411251. CrossRef Medline

Floresco SB, Blaha CD, Yang CR, Phillips AG (2001) Dopamine D1 and NMDA receptors mediate potentiation of basolateral amygdala-evoked firing in nucleus accumbens neurons. J Neurosci 21:6370-7376. Medline

Ford CP, Mark GP, Williams JT (2006) Properties and opioid inhibition of mesolimbic dopamine neurons vary according to target location. J Neurosci 26:2788-2797. CrossRef Medline

Frankland PW, O’Brien C, Ohno M, Kirkwood A, Silva AJ (2001) AlphaCaMKII-dependent plasticity in the cortex is required for permanent memory. Nature 411:309-313. CrossRef Medline

Frenois F, Stinus L, Di Blasi F, Cador M, Le Moine C (2005) A specific limbic circuit underlies opiate withdrawal memories. J Neurosci 25:1366-1374. CrossRef Medline

Fricks-Gleason AN, Marshall JF (2011) Role of dopamine D1 receptors in the activation of nucleus accumbens extracellular signal-regulated kinase (ERK) by cocaine-paired contextual cues. Neuropsychopharmacology 36 : 434-444. CrossRef Medline

Girault JA, Valjent E, Caboche J, Hervé D (2007) ERK2: a logical AND gate critical for drug-induced plasticity? Curr Opin Pharmacol 7:77-85. CrossRef Medline

Greenstein R, Novak G, Seeman P (2007) Amphetamine sensitization elevates CaMKIIbeta mRNA. Synapse 61:827-834. CrossRef Medline

$\mathrm{Gu}$ Z, Yan Z (2004) Bidirectional regulation of Ca2+/calmodulindependent protein kinase II activity by dopamine D4 receptors in prefrontal cortex. Mol Pharmacol 66:948-955. CrossRef Medline

Hernandez-Lopez S, Tkatch T, Perez-Garci E, Galarraga E, Bargas J, Hamm $\mathrm{H}$, Surmeier DJ (2000) $\mathrm{D}_{2}$ dopamine receptors in striatal medium spiny neurons reduce $\mathrm{L}$-type $\mathrm{Ca}^{2+}$ currents and excitability via a novel PLC $\beta 1-$ $\mathrm{IP}_{3}$-calcineurin-signaling cascade. J Neurosci 20:8987-8995. Medline

Ibba F, Vinci S, Spiga S, Peana AT, Assaretti AR, Spina L, Longoni R, Acquas E (2009) Ethanol-induced extracellular signal regulated kinase: role of dopamine D1 receptors. Alcohol Clin Exp Res 33:858-867. CrossRef Medline

Ishida A, Kameshita I, Okuno S, Kitani T, Fujisawa H (1995) A novel, highly specific and potent inhibitor of calmodulin-dependent protein kinase II. Biochem Biophys Res Commun 212:806-812. CrossRef Medline

Kelly A, Laroche S, Davis S (2003) Activation of mitogen-activated protein kinase/extracellular signal-regulated kinase in hippocampal circuitry is required for consolidation and reconsolidation of recognition memory. J Neurosci 23:5354-5360. Medline

Lauzon NM, Ahmad T, Laviolette SR (2012) Dopamine D4 receptor transmission in the prefrontal cortex controls the salience of emotional memory via modulation of calcium calmodulin-dependent kinase II. Cereb Cortex 22:2486-2494. CrossRef Medline

Laviolette SR, van der Kooy D (2003) Blockade of mesolimbic dopamine transmission dramatically increases sensitivity to the rewarding effects of nicotine in the ventral tegmental area. Mol Psychiatry 8:50-59, 9. CrossRef Medline

Laviolette SR, van der Kooy D (2004) GABA receptors signal bidirectional reward transmission from the ventral tegmental area to the tegmental pedunculopontine nucleus as a function of opiate state. Eur J Neurosci 20:2179-2187. CrossRef Medline

Lee AK (1996) Dopamine (D2) receptor regulation of intracellular calcium and membrane capacitance changes in rat melanotrophs. J Physiology 495:627-640.

Li F, Wang XS, Dai RP, Zhang JY, Zhou XF, Hao W, Li CQ (2011) The activation of NMDA receptor-ERK pathway in the central amygdala is required for the expression of morphine-conditioned place preference in the rat. Neurotox Res 20:362-371. CrossRef Medline

Li T, Hou Y, Cao W, Yan CX, Chen T, Li SB (2010) Naloxone-precipitated withdrawal enhances ERK phosphorylation in prefrontal association cortex and accumbens nucleus of morphine-dependent mice. Neurosci Lett 468:348-352. CrossRef Medline
Lintas A, Chi N, Lauzon NM, Bishop SF, Gholizadeh S, Sun N, Tan H, Laviolette SR (2011) Identification of a dopamine receptor-mediated opiate reward memory switch in the basolateral amygdala-nucleus accumbens circuit. J Neurosci 31:11172-11183. CrossRef Medline

Lintas A, Chi N, Lauzon NM, Bishop SF, Sun N, Tan H, Laviolette SR (2012) Inputs from the basolateral amygdala to the nucleus accumbens shell control opiate reward magnitude via differential dopamine D1 or D2 receptor transmission. Eur J Neurosci 35:279-290. CrossRef Medline

Lisman J, Schulman H, Cline H (2002) The molecular basis of CaMKII function in synaptic and behavioral memory. Nat Rev Neurosci 3:175190. CrossRef Medline

Liu XY, Mao LM, Zhang GC, Papasian CJ, Fibuch EE, Lan HX, Zhou HF, Xu M, Wang JQ (2009) Activity-dependent modulation of limbic dopamine D3 receptors by CaMKII. Neuron 61:425-438. CrossRef Medline

Liu Z, Zhang JJ, Liu XD, Yu LC (2012a) Inhibition of CaMKII activity in the nucleus accumbens shell blocks the reinstatement of morphine-seeking behavior in rats. Neurosci Lett 518:167-171. CrossRef Medline

Liu Z, Liu XD, Zhang JJ, Yu LC (2012b) Increases in $\alpha$ CaMKII phosphorylated on Thr286 in the nucleus accumbens shell but not the core during priming-induced reinstatement of morphine-seeking in rats. Neurosci Lett 526:39-44. CrossRef Medline

Lou L, Zhou T, Wang P, Pei G (1999) Modulation of Ca2+/calmodulindependent protein kinase II activity by acute and chronic morphine administration in rat hippocampus: differential regulation of alpha and beta isoforms. Mol Pharmacol 55:557-563. Medline

Lu L, Zeng S, Liu D, Ceng X (2000) Inhibition of the amygdala and hippocampal calcium/calmodulin-dependent protein kinase II attenuates the dependence and relapse to morphine differently in rats. Neurosci Lett 291:191-195. CrossRef Medline

Lu L, Hope BT, Dempsey J, Liu SY, Bossert JM, Shaham Y (2005) Central amygdala ERK signaling pathway is critical to incubation of cocaine craving. Nat Neurosci 8:212-219. CrossRef Medline

Ma W, Zheng WH, Powell K, Jhamandas K, Quirion R (2001) Chronic morphine exposure increases the phosphorylation of MAP kinases and the transcription factor CREB in dorsal root ganglion neurons: an in vitro and in vivo study. Eur J Neurosci 14:1091-1104. Medline

Miller CA, Marshall JF (2005) Molecular substrates for retrieval and reconsolidation of cocaine-associated contextual memory. Neuron 47:873884. CrossRef Medline

Mizoguchi H, Yamada K, Mizuno M, Mizuno T, Nitta A, Noda Y, Nabeshima $\mathrm{T}$ (2004) Regulations of methamphetamine reward by extracellular signal-regulated kinase 1/2/ets-like gene-1 signaling pathway via the activation of dopamine receptors. Mol Pharmacol 65:1293-1301. CrossRef Medline

Moriya T, Kouzu Y, Shibata S, Kadotani H, Fukunaga K, Miyamoto E, Yoshioka T (2000) Close linkage between calcium/calmodulin kinase II $\alpha / \beta$ and NMDA-2A receptors in the lateral amygdala for retrieval of auditory fear conditioning. Eur J Neurosci 12:3307-3314. CrossRef Medline

Muller DL, Unterwald EM (2004) In vivo regulation of extracellular signalregulated protein kinase (ERK) and protein kinase B (Akt) phosphorylation by acute and chronic morphine. J Pharmacol Exp Ther 310:774-782. CrossRef Medline

Nader K, van der Kooy D (1997) Deprivation state switches the neurobiological substrates mediating opiate reward in the ventral tegmental area. J Neurosci 17:383-390. Medline

Narita M, Matsumura Y, Ozaki S, Ise Y, Yajima Y, Suzuki T (2004) Role of the calcium/calmodulin-dependent protein kinase II (CaMKII) in the morphine-induced pharmacological effects in the mouse. Neuroscience 126:415-421. CrossRef Medline

Novak G, Seeman P (2010) Hyperactive mice show elevated D2(High) receptors, a model for schizophrenia: calcium/calmodulin-dependent kinase II alpha knockouts. Synapse 64:794-800. CrossRef Medline

Olmstead MC, Franklin KB (1997) The development of a conditioned place preference to morphine: effects of microinjections into various CNS sites. Behav Neurosci 111:1324-1334. CrossRef Medline

Papaleo F, Yang F, Garcia S, Chen J, Lu B, Crawley JN, Weinberger DR (2012) Dysbindin-1 modulates prefrontal cortical activity and schizophrenia-like behaviors via dopamine/D2 pathways. Mol Psychiatry 17: 85-98. CrossRef Medline

Paxinos G, Watson C (2005) The rat brain in stereotaxic coordinates. Amsterdam: Elsevier Academic.

Rosenkranz JA, Grace AA (2001) Dopamine attenuates prefrontal cortical 
suppression of sensory inputs to the basolateral amygdala of rats. J Neurosci 21:4090-4103. Medline

Rosenkranz JA, Grace AA (2003) Affective conditioning in the basolateral amygdala of anesthetized rats is modulated by dopamine and prefrontal cortical inputs. Ann N Y Acad Sci 985:488-491. Medline

Seo YJ, Kwon MS, Choi HW, Jang JE, Lee JK, Jung JS, Park SH, Suh HW (2008) The differential effect of morphine and beta-endorphin administered intracerebroventricularly on pERK and pCaMK-II expression induced by various nociceptive stimuli in mice brains. Neuropeptides 42 : 319-330. CrossRef Medline

Shen K, Meyer T (1999) Dynamic control of CaMKII translocation and localization in hippocampal neurons by NMDA receptor stimulation. Science 284:162-166. CrossRef Medline

Stuber GD, Sparta DR, Stamatakis AM, van Leeuwen WA, Hardjoprajitno JE, Cho S, Tye KM, Kempadoo KA, Zhang F, Deisseroth K, Bonci A (2011) Excitatory transmission from the amygdala to nucleus accumbens facilitates reward seeking. Nature 475:377-380. CrossRef Medline

Sun N, Laviolette SR (2012) Inactivation of the basolateral amygdala during opiate reward learning disinhibits prelimbic cortical neurons and modulates associative memory extinction. Psychopharmacology 222:645-661. CrossRef Medline
Valjent E, Pascoli V, Svenningsson P, Paul S, Enslen H, Corvol JC, Stipanovich A, Caboche J, Lombroso PJ, Nairn AC, Greengard P, Hervé D, Girault JA (2005) Regulation of a protein phosphatase cascade allows convergent dopamine and glutamate signals to activate ERK in the striatum. Proc Natl Acad Sci U S A 102:491-496. CrossRef Medline

Valjent E, Corbillé AG, Bertran-Gonzalez J, Hervé D, Girault JA (2006) Inhibition of ERK pathway or protein synthesis during re-exposure to drugs of abuse erases previously learned place preference. Proc Natl Acad Sci U S A 103:2932-2937. CrossRef Medline

Wang ZJ, Wang LX (2006) Phosphorylation: a molecular switch in opioid tolerance. Life Sci 79:1681-1691. CrossRef Medline

Wang Z, Chabot JG, Quirion R (2011) On the possible role of ERK, p38 and CaMKII in the regulation of CGRP expression in morphine-tolerant rats. Mol Pain 7:68. CrossRef Medline

Wanjerkhede SM, Bapi RS (2008) Modeling the sub-cellular signaling pathways involved in reinforcement learning at the striatum. Prog Brain Res 168:193-206. CrossRef Medline

Zhong W, Dong Z, Tian M, Cao J, Xu T, Xu L, Luo J (2006) Opiate withdrawal induces dynamic expressions of AMPA receptors and its regulatory molecule CaMKII $\alpha$ in hippocampal synapses. Life Sci 79: 861-869. CrossRef Medline 